\title{
Predicting green building performance over time: data mining untapped information in LEED
}

\author{
A. Jeerage ${ }^{1}$, B. Erwine ${ }^{1}$, S. Mallory ${ }^{2} \&$ V. Agarwal $^{1}$ \\ ${ }^{1}$ Paladino and Company, USA \\ ${ }^{2}$ City of Seattle Department of Planning \& Development, USA
}

\begin{abstract}
This paper will present a method for data mining building performance information available in the LEED $^{\mathrm{TM}}$ rating system project applications to show predicted environmental impact and improved performance over time. A study initiated by the City of Seattle analyzed data from over 50 LEED projects within the city limits to quantify the climate change impact of LEED buildings, developing aggregate performance predictions for water, energy and solid waste measures and savings. This paper demonstrates the efficacy of mining LEED derived performance data to make predictions about environmental impact, including carbon reduction, of green building programs using the City of Seattle Performance Evaluation Program as an example. This paper probes key findings regarding the most common green building measures, aggregated savings, the market penetration of specific strategies, and opportunities lost. The LEED Documentation Data Mining Methodology ${ }^{\circledR}$ magnifies its value if used to compare varying building cohorts to identify regional, programmatic, and ownerrelated performance patterns and to inform continuous improvement of sustainable building approaches. The paper explores how this data mining methodology could be adapted and developed for any rating system and any cohort of buildings, and thus utilized to predict sustainable design and related climate impacts of building programs.
\end{abstract}

Keywords: data-mining, sustainability, LEED. 


\section{Introduction}

Buildings are major users of energy and materials that produce by-product greenhouse gas emissions; close to $40 \%$ of annual $\mathrm{CO}_{2}$ emissions are a result of building construction and operations. Therefore, there is a need to understand the potential of building rating systems and programs to slow the growth rate of greenhouse gases and meet climate change targets.

The most accurate method for evaluating building performance is through monitoring utility consumption, cost and occupant satisfaction for a large portfolio of buildings over time. However, there are limitations and challenges to this process. First, the process is time consuming and costly, representing a significant annual investment throughout the life of the building. Second, there is no clear agreement on standardized baselines or methods to estimate savings.

However, there are a variety of green building rating systems that establish standardized procedures to predict performance of green building designs. Rating systems, such the U.S. Green Building Council's Leadership in Energy and Environmental Design (LEED), collect data based on standardized calculations of energy, water, and materials savings, with prescribed baseline definitions and calculation methods. This data is available now and can be "mined" to provide a valuable window into expected building performance over time. The large number of buildings that have participated in this rating system provides a significant database of information that can inform responsible use of energy and resources, show the need for policy changes, and demonstrate whether the investment in broad green building programs delivers the climate change goals that are desired.

Section 2 provides background information on the project history and the LEED program, and describes the methodology and analysis tool used for the study. Section 3 depicts representative graphs and data summaries that are generated by the tool.

\section{City of Seattle performance evaluation program}

A study initiated by the City of Seattle analyzed data from over 50 LEED projects within the city limits to quantify the climate change impact of LEED buildings, and to develop aggregate performance profiles on water, energy, and material savings. This analysis provided insight into the most common green building measures and market penetration of specific strategies, as well as opportunities lost.

\subsection{Background information}

The City of Seattle initiated this study in 2005. Paladino and Company performed the study, which consisted of data mining predicted building performance from the LEED applications of 15 buildings within the City of Seattle limits. The study summarized and aggregated the LEED application data 
to evaluate the potential long-term impacts of green buildings on the City's infrastructure and resources.

Recognizing that the value of the study would increase over time, as more LEED buildings are added to the database analysis, the City became interested in an annual study of LEED projects. The City worked with Paladino to develop a tool so that the analysis could be easily performed on an annual basis. Another element of the tool development was to integrate a filtering feature to allow segmentation of building cohorts for analysis and comparison. For example, the data could be filtered by date to determine measures implemented before and after a code change; or the data could be filtered to compare office buildings with school buildings. Filtering the data allows the City to understand the most commonly implemented sustainable design strategies, as well as identify potential conservation measures and opportunities not currently implemented by Seattle buildings.

\subsection{LEED rating system}

The LEED rating system, developed by the U.S. Green Building Council, is the predominantly-used program for rating the design, construction and operation of green buildings in the United States. LEED is a third-party certification program and is a benchmark tool for the evaluation of sustainability, not a design guideline.

LEED utilizes a point-based approach with different rating system "products" specifically tailored to various building construction types, such as new construction, commercial interiors, and existing buildings. The LEED rating system is organized into five major categories: 1) Sustainable Sites, 2) Water Efficiency, 3) Energy \& Atmosphere, 4) Materials \& Resources, and 5) Indoor Air Quality. Credits and associated points are available in each category for achieving specific performance or prescriptive criteria.

Because the City of Seattle was interested in the potential impact that new green buildings have on City infrastructure services like water and electricity, they decided to track buildings certified under three LEED rating systems: New Construction (NC), Core \& Shell (CS), and Commercial Interiors (CI). Although many credits are similar across these rating systems, some credits are unique to a specific system. For example, credits related to stormwater are found only in the NC and CS rating systems.

Within each system, projects receive a rating of Certified, Silver, Gold, or Platinum, depending on the number of points achieved. In order for a project to achieve a rating, the design must meet a set of prerequisite credits, supplemented by a group of credits commensurate with that rating level. Point achievement is validated through the development of the LEED application, which consists of required documentation for each credit that the design pursued and achieved. A LEED Submittal Template for each credit summarizes a majority of the required information, but the project team is also required to provide supplemental documentation. 


\subsection{Methodology}

Paladino developed a LEED Documentation Data Mining Methodology to extract and aggregate the wealth of data found in a single LEED application. The methodology is executed through a data mining tool, which takes standardized inputs from individual LEED applications, aggregates the data from multiple projects, and outputs a single report based on the chosen cohort of buildings.

To obtain the LEED applications, Paladino referenced the U.S. Green Building Council website, which publishes a list of certified projects. Projects may confidentially register with the USGBC, and their contact information and project data is not available. Confidential projects are not included in this study. Teams from all available projects located within the City of Seattle, up to October 2009, were contacted to request participation in the study. Most project teams agreed to participate, and to provide their final LEED application data and scorecard for input into the study.

After the project LEED documentation is received, credits achieved, points earned and additional documentation data are entered into a standardized input sheet in the tool. The tool for analyzing the data and outputting reports is designed in Excel using embedded macros and pivot tables. The pivot table creates a mechanism that enables data filtering across several parameters, including LEED rating system used, rating achieved, building owner, zip code, and certification date. Based on the selected filters, the tool produces standardized outputs reporting calculated savings for water, energy, carbon emissions, and materials.

The tool tracks the number of projects achieving any specific credit compared to the total number of projects in that cohort. However, for targeted credits, the tool also provides detailed information on how the credit intent was satisfied, supplying a wealth of data for predicting total savings and identifying commonly-implemented technologies.

Currently, the data from 54 LEED projects has been analyzed using the spreadsheet tool. These projects use LEED for ${ }^{\text {New }}$ Construction (NC), Core and Shell (CS), or Commercial Interiors (CI) rating systems as shown in Table 1. The New Construction system addresses new building construction and substantial additions or renovations; Core and Shell addresses construction that impacts only a portion of the building, such as structure, building envelope, and HVAC systems; and Commercial Interiors addresses the tenant improvement

Table 1: $\quad$ City of Seattle LEED portfolio summary.

\begin{tabular}{|c|c|}
\hline Number of NC Projects & 33 \\
\hline Number of CS Projects & 7 \\
\hline Number of Cl Projects & 14 \\
\hline Total Number of Projects & $\mathbf{5 4}$ \\
\hline Total Square Footage & $4,238,540$ \\
\hline
\end{tabular}


market and encompasses interior spaces. The New Construction and Core and Shell projects are reported together as their credits are identical for the targeted credits analyzed. Because the LEED-CI credits differ somewhat from $\mathrm{NC}$ and $\mathrm{CS}, \mathrm{CI}$ project data is analyzed separately and then added to the $\mathrm{NC} / \mathrm{CS}$ data as appropriate. Information gathering on the LEED for Commercial Interiors projects occurred retroactively, so not all publicly available CI projects are included prior to 2008. A majority of projects currently in this study use the New Construction rating system.

\section{Performance profiles}

The City uses this evaluation tool and its resulting reports to develop aggregate performance profiles of water, energy and solid waste measures and savings. Each report profile consists of specific credits within the LEED rating systems. Although the data from a single project is interesting in itself, the real value in this type of reporting comes from analyses of the data over time or between different cohorts of buildings. These comparisons can indicate trends in design and construction choices over time or over different building types or geographic locations.

Figure 1 shows the LEED-NC project certifications in the City of Seattle for each year from 2003 through 2008.

\subsection{Water savings and strategies}

Water management and conservation are a critical component of green buildings. Buildings have many water use functions, from irrigation to wastewater and indoor plumbing fixtures. Process water is another component of water use that can be quite high in certain building types, such as industrial buildings or fire stations.

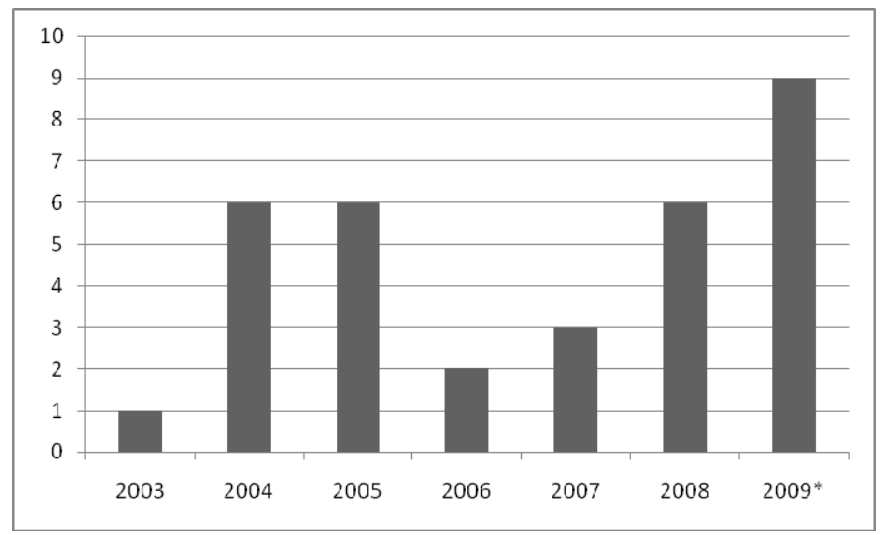

Figure 1: Number of LEED-NC projects certified over time. *2009 information does not include projects certified after October 2009. 
Green buildings demonstrate water conservation strategies in many different and creative ways. LEED offers points based on an overall percentage of water use reduction for both irrigation and indoor plumbing when compared to a building with EPACT water consuming fixtures and systems.

\subsubsection{Irrigation}

The irrigation credit is only available to projects certified under LEED for New Construction and Core \& Shell projects, because projects using the Commercial Interiors rating system do not include exterior landscaped areas. Of the 40 total NC \& CS projects, 14 projects reduced potable water consumption used for irrigation by at least $50 \%$, and 21 projects did not use potable water for irrigation or had no permanent irrigation system.

Seattle is a city with plentiful rainfall; however, it is still common to see irrigation systems installed to water non-native plant species. LEED buildings in Seattle utilized a range of water saving strategies, summarized in Figure 2. Note that projects often implemented multiple strategies, thus the total number of strategies used is higher than the 40 projects that achieved the credit.

\subsubsection{Indoor water use}

All three rating systems ( $\mathrm{NC}, \mathrm{CS}, \& \mathrm{CI})$ utilize an identical method to estimate water use reduction from use of low-flow indoor plumbing fixtures. The estimated water use reduction is a percent calculation using the gallons per use for installed fixtures compared to a standard baseline, and estimates of usage are based on the total occupancy and occupancy type.

Figure 3 shows indoor plumbing water savings across the entire portfolio and highlights which strategies provide a significant percentage of water savings. For instance, $14 \%$ of water savings comes from rainwater harvesting, which is

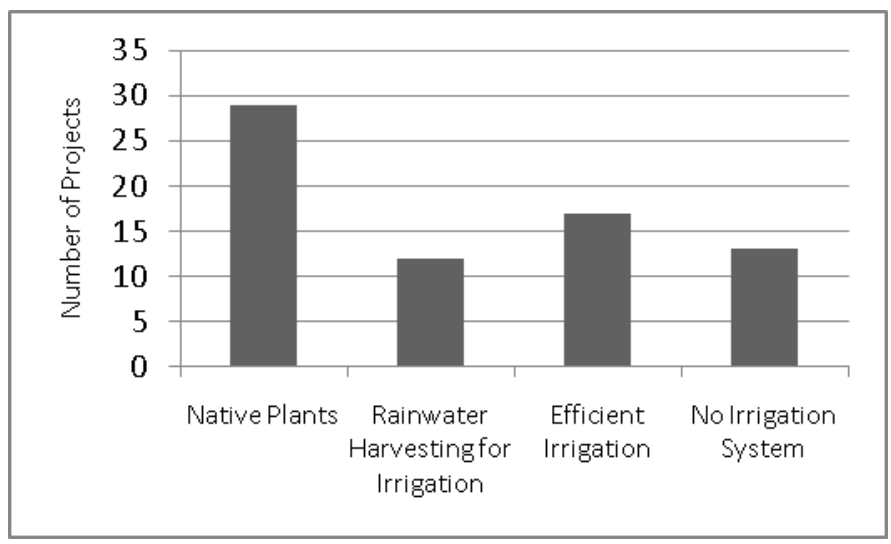

Figure 2: Key irrigation water saving strategies implemented for City of Seattle LEED buildings 2003-2009. 


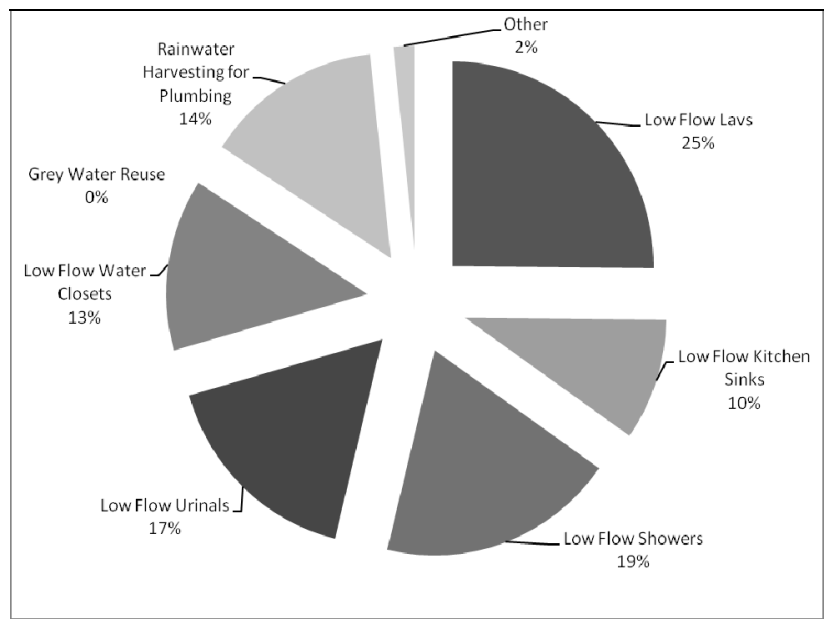

Figure 3: Percent savings by strategy implemented for City of Seattle LEED buildings 2003-2009.

slightly higher than the $13 \%$ savings from low-flow water closets. However, these percentages do not give any indication of how many projects are implementing a given strategy. A comparison between water savings and number of projects implementing each strategy, as in Figure 4, shows that although the savings are almost equivalent, almost four times as many projects install low-flow water closets, as compared to the number that implement rainwater harvesting. This fact indicates an example of an underutilized strategy, with a potentially large impact on overall water savings for a building portfolio.

\subsection{Energy}

\subsubsection{Overall energy savings}

The LEED for New Construction and Core \& Shell rating systems offer a credit specific to the optimization of energy performance, which is achieved by demonstrating predicted energy savings. Achievement of this credit reduces environmental impacts associated with excessive energy use. Projects must demonstrate increasing levels of performance above an ASHRAE (American Society of Heating, Refrigerating and Air-Conditional Engineers) Standard 90.1 baseline through a whole-building energy simulation.

The LEED for Commercial Interiors rating system, on the other hand, does not require an overall energy analysis. Instead, project teams show energy savings through reduction in selected end uses, such as lighting power density, lighting controls, and equipment installed. These savings are predicted with standardized calculations and do not require computer simulation.

Figure 5 shows the number of projects using the NC or CS rating system each year in the study (total bar height) and the ratio of those projects that did or did not achieve energy savings when compared to ASHRAE 90.1. The overall 


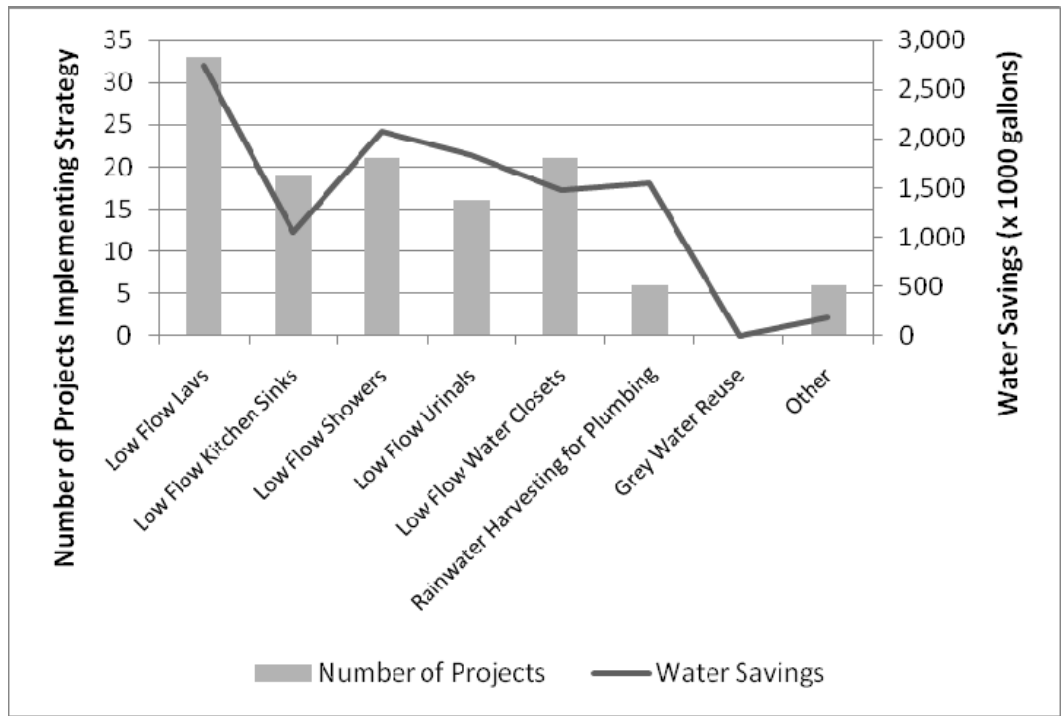

Figure 4: Key strategies implemented and water savings for City of Seattle LEED buildings 2003-2009.

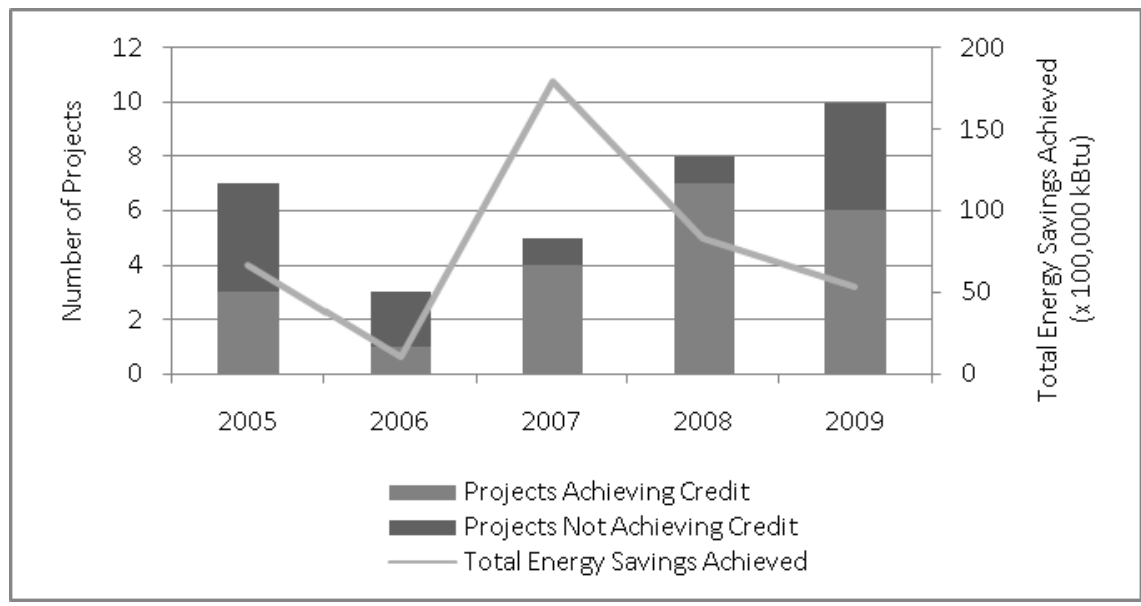

Figure 5: Energy savings over time for City of Seattle LEED-NC and CS buildings 2005-2009.

energy savings per project fluctuates and does not seem strongly correlated with the number of projects achieving the credit. However, in 2007, one Seattle LEED building demonstrated considerably high energy savings than the other projects. Such outliers can potentially obscure data trends. Omitting this project reveals a closer relationship between energy savings and the total number of projects, as seen in Figure 6. 


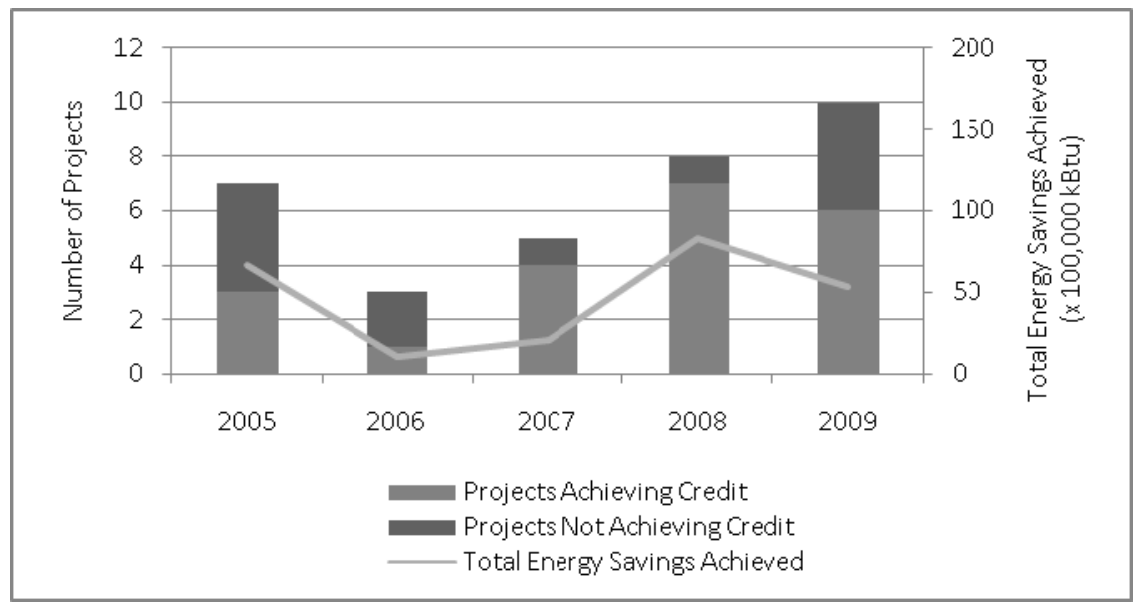

Figure 6: Energy savings over time for City of Seattle LEED-NC and CS buildings 2005-2009 with outlier 2007 project removed.

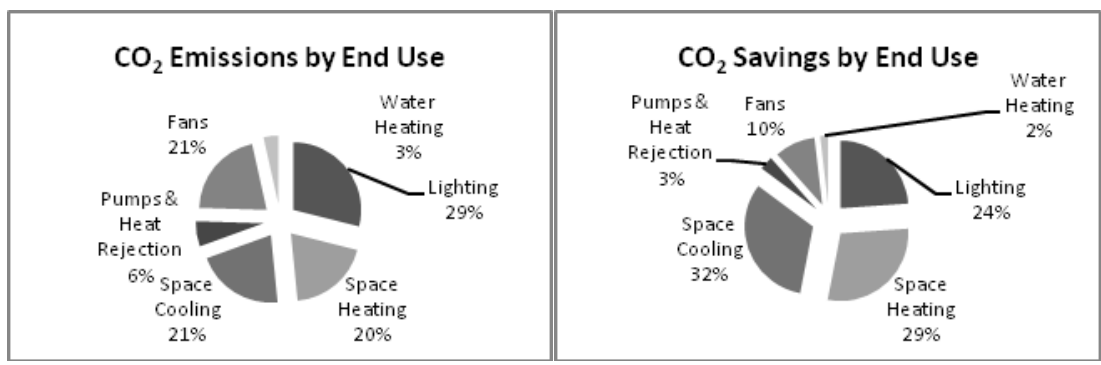

Figure 7: $\quad \mathrm{CO}_{2}$ profile for City of Seattle LEED buildings 2003-2009.

\subsubsection{Carbon reporting}

Estimates on carbon emissions are derived directly from the LEED projections of energy use, as LEED does not currently require documentation of carbon emissions reduction. Using conversion factors provided by the City of Seattle, a profile on carbon emissions and savings from LEED buildings is developed. This information can validate progress against the City's carbon reduction goals.

Figure 7 shows pie charts of $\mathrm{CO}_{2}$ emissions by end use compared to $\mathrm{CO}_{2}$ savings by end use. Most areas with large contributions to emissions, such as lighting, heating, and cooling, also have comparable or higher savings percentages. However, this trend is not followed for fans that make up $21 \%$ of $\mathrm{CO}_{2}$ emissions yet only contribute to $10 \%$ of the $\mathrm{CO}_{2}$ savings by end use.

\subsubsection{Renewable energy}

LEED also awards points to projects that install renewable energy systems that offset a percentage of the overall energy use, such as solar panels or wind turbines. This is a credit with very low achievement; within the cohort of City of 
Seattle LEED Portfolio analyzed, only $12.5 \%$ of projects installed a renewable system that provided a minimum of $2.5 \%$ of the total building energy use.

\subsection{Materials}

There are several credits in all rating systems associated with materials, and two of these credits were tracked in detail for this study.

\subsubsection{Construction waste management}

The City of Seattle has set ambitious goals to increase the degree of recycling and waste reduction from construction-related activities. All buildings, regardless of whether they are pursuing LEED certification, contribute to meeting the City's Zero Waste Strategy, which has a 70\% of total construction waste recycling target by 2025. According to the City's Department of Planning and Development, because there are so few landfills with free capacity, roughly $80 \%$ of City waste is exported.

The City's ambitious goals are reflected in construction waste diversion from LEED projects. In the complete City of Seattle LEED Portfolio, $96 \%$ of projects diverted a minimum of $50 \%$ of construction waste from landfills.

Figure 8 shows a bar chart with the total bar height equaling annual percentage of construction waste diverted from LEED-NC and CS projects. The chart shows a consistent diversion level above $70 \%$. The bar is subdivided to show what percentage (by weight) of construction waste was recycled through commingling, as source-separated concrete, or is another material recycled by source separation. The reduction in the waste diverted by commingling appears to be decreasing with time.

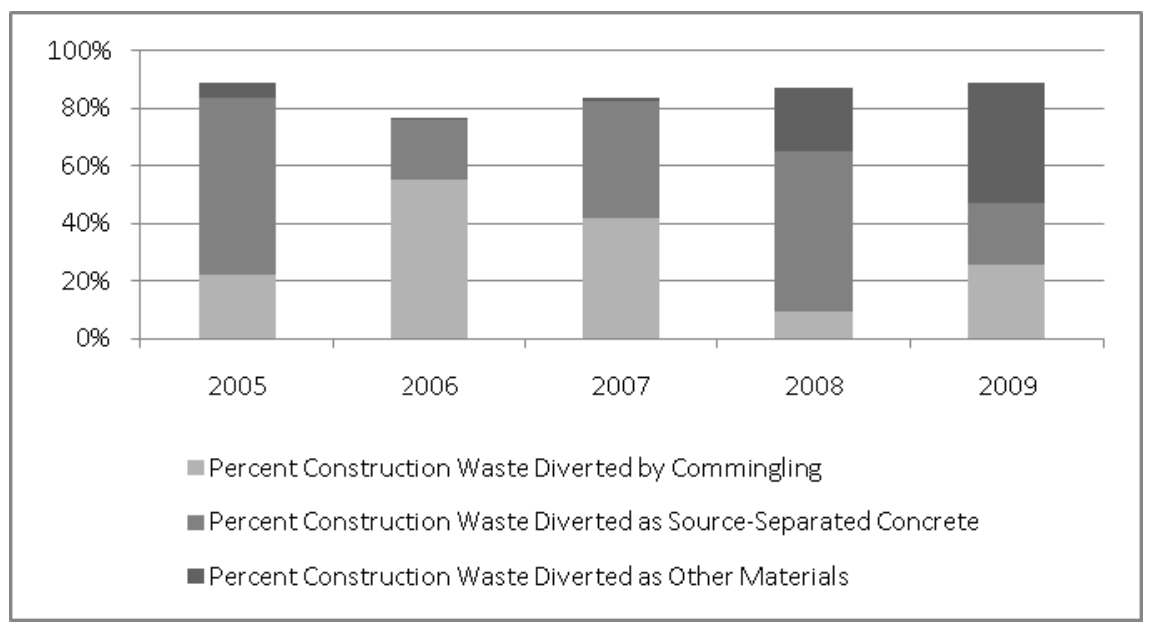

Figure 8: Construction waste diversion profile for City of Seattle LEED-NC and CS buildings 2005-2009. 


\subsubsection{Materials with recycled content}

Using materials with recycled content helps to minimize impacts resulting from extraction and processing of virgin materials. To evaluate the LEED project impact on recycled product purchasing, the tool tracks the value of recycled materials incorporated into projects. The analysis indicates that the complete City of Seattle LEED Portfolio used materials with a recycled content value totaling over $\$ 39$ million dollars.

\section{Conclusion}

Although LEED documentation is originally generated to demonstrate compliance with sustainable building design objectives for individual project ratings, in aggregate the data reported in the documentation represents a gold mine of information that can be mined to extract trends in implemented measures and predicted and actual savings. The rigorous, standardized calculation methods and documentation requirements of the LEED system ensure that savings calculations and reporting protocols are consistent across all rated buildings. Further, the evolution of LEED to an online documentation process allows this data to be made accessible for research purposes.

Building owners and design/construction teams across the United States and throughout the world are choosing LEED as a method to validate their green building successes. Whether the decision to pursue LEED is mandated or voluntary, a growing number of projects, project teams will document the projected building performance based on design decisions and will provide actual data on construction waste and construction materials. This information is available now in a growing database of thousands of buildings. Aggregating and analyzing these individual LEED applications can reveal green building performance trends for different cohorts of buildings and provide information about the market penetration of specific green building strategies and their associated savings.

Comparisons between different cohorts can provide information about how these trends vary across geographical locations, building types, year of construction, and even building owner. The possibilities and applications are vast. Tapping into this available information is an important first step to understanding the potential buildings have to reduce environmental impacts on our planet. 